\title{
ADDICTIVE POTENTIAL OF ONLINE-GAMBLING. A PREVALENCE STUDY FROM AUSTRIA
}

\author{
Kurosch Yazdi \& Christian Katzian \\ Department of Psychiatry - Specialization Addiction Medicine, Kepler University Hospital, Linz, Austria
}

received: 21.3.2017;

revised: 24.7.2017;

accepted: 7.8.2017

\section{SUMMARY}

There are hints, that online-gambling has a higher addictive potential than offline-gambling. In this study prevalence and sociodemographic distribution of online- vs. offline-gambling in Austria are gathered and possible relations discussed. Problematic gambling-behavior was assessed via Lie-and-Bet questionnaire from Johnson. The results indicate a tendency of younger gamblers and particularly problematic gamblers towards online-gambling. Considering the substantial addictive potential of online-gambling and hints of a future trend away from offline- towards online-gambling, preventive measures like public restrictions for online providers and awareness campaigns for consumers about the dangers of online-gambling offers are reasonable.

Key words: gambling - online - offline - lie-and-bet-addiction - prevalence

$$
* * * * *
$$

\section{INTRODUCTION}

Gambling is classified as an addiction disorder in DSM-5. In the ICD-10 it is listed as impulse disorder under F63. There are hints of higher addictive potential of online gambling in comparison to offline gambling. This might be the result of more local and temporal availability, anonymity, cashless payment and less government control (Griffiths et al. 2009, Kairouz et al. 2012). In accordance to our clinical experience in the treatment of pathological gamblers we presumed a higher percentage of addicted or at least problematic gamblers among online gamblers. Furthermore, we postulated online gamblers to be younger. Studies from other countries show an increase of gambling disorder for young people. A recent Canadian paper pointed out, that young people are increasingly being seduced by the internet to gambling and that the prevalence of problematic gamblers is higher online than offline (Elton-Marshall et al. 2016). A few years ago, an Austrian survey already showed a tendency of younger gamblers towards online gambling and hinted at higher addictive potential with $8.2 \%$ pathological gambling among online gamblers versus $1.56 \%$ among all gamblers (Kalke et al. 2011).

In our study we raised the prevalence and sociodemographic distribution of online versus offline gambling in Austria.

\section{METHOD}

3043 individuals in Austria were questioned face to face and in-home from May to June 2013. The interviews were realized by IMAS International, an Austrian company for market and social analysis. A representative sample was defined in accordance to the sociodemographic distribution in Austria. To capture problematic or pathological gamblers, Johnson's Lieand-Bet Questionnaire (Johnson et al. 1997) was used containing the following two questions:

- Have you ever had to lie to people important to you about how much you gambled?

- Have you ever felt the need to bet more and more money?

A positive reply to one of these two questions is a distinct hint for a problematic gambling behavior in the sense of danger of addiction (Götestam et al. 2004). Further on, type of gambling and sociodemographic data like age, sex, education, occupation, income, marital status and migration background were raised.

\section{RESULTS}

Our findings show a binomial asymmetric distribution. The confidence intervals were calculated by Clopper-Pearson. The main findings of online versus offline gambling are listed in table 1. Summarizing the significant differences, online gamblers were younger, male, more educated and generally more online. Other differences like migration background, income, occupation and local differences within Austria were not significant.

Out of the 240 participants showing problematic gambling behavior by answering one or both Lie-andBet questions positively, $9 \%$ played mostly online $(n=22)$. Due to the small number, no significant differences among these can be offered. But problematic online gamblers seemed to be even younger than nonproblematic online gambler, single and more often male. Interestingly, $31 \%$ of all online gamblers showed a problematic gambling behavior, in comparison to only $18 \%$ of the offline gambler. 
Table 1. Online versus offline gambling

\begin{tabular}{lccc}
\hline Sociodemographic data & Offline gambling \% (n) & Online gambling \% (n) & Level of significance \\
\hline Total & $100(1187)$ & $100(72)$ & $\mathrm{p}<0.05$ \\
Age 16-29 & $15.75(187)$ & $36.11(26)$ & $\mathrm{p}<0.05$ \\
Age 30-49 & $40.02(475)$ & $52.78(38)$ & $\mathrm{p}<0.05$ \\
Age $>50$ & $42.80(508)$ & $11.11(8)$ & $\mathrm{p}<0.05$ \\
Female & $46.76(555)$ & $13.89(10)$ & $\mathrm{p}<0.05$ \\
Male & $51.56(612)$ & $86.11(62)$ & $\mathrm{p}<0.05$ \\
A-level, higher education & $22.07(262)$ & $36.11(26)$ & $\mathrm{p}<0.05$ \\
Vocational school, secondary school & $47.35(562)$ & $47.22(34)$ & $\mathrm{n} . \mathrm{s}$. \\
Compulsory school & $29.40(349)$ & $16.67(12)$ & $\mathrm{p}<0.05$ \\
Intensively online & $54.68(649)$ & $86.11(62)$ & $\mathrm{p}<0.05$ \\
Moderately online & $19.46(231)$ & $9.72(7)$ & $\mathrm{n} . \mathrm{s}$. \\
Rarely online & $25.19(299)$ & $4.17(3)$ & $\mathrm{p}<0.05$ \\
Lie-and-Bet positive & $18.37(218)$ & $30.56(22)$ & $\mathrm{p}<0.05$ \\
\hline
\end{tabular}

Main sociodemographic differences between online versus offline gambling in Austria. n.s. (not significant).

Lie-and-Bet positive (positive answer on one or both Lie-and Bet questions)

\section{DISCUSSION}

Younger gambling consumers and especially problematic gamblers seem to tend towards online gambling. As Griffiths stated, this can be explained by the generally stronger affinity of young people towards internet (Griffiths et al. 2009). As there is no reason to believe, that online gamblers will switch to offline gambling when getting older, the ratio of online versus offline gambling should reverse in favor of online in the coming years. In accordance with other authors we postulate a higher addiction potential of online gambling (Elton-Marshall et al. 2016, Griffiths et al. 2009, Kairouz et al. 2012). As a consequence, in future the prevalence of excessive or pathological gambling might rise. Furthermore, many online gambling platforms offer little quality standards in regard to player protection e.g. age limit, built-in alert systems or the possibility of self-locking (Malischnig 2014). The fact, that online gamblers tend to be young and single males (Kairouz et al. 2012) needs to be considered regarding prevention measures. Adolescents and young adults need to be informed about the possible dangers of online gambling. And there is a need for more government control and restrictions for online gambling providers.

\section{Contribution of individual authors:}

Kurosch Yazdi contributed to all stages of this paper.

Christian Katzian contributed to literature search, interpretation of data and preparing manuscript.

\section{Acknowledgements:}

Data collection for this study was carried out feebased by IMAS International, an Austrian company engaged in market and social analyses. The costs of data collection were funded by the research fund of the clinic for gambling addiction of pro mente Upper Austria, which in turn is served by earmarked donations from Admiral Casinos \& Entertainment Corporation. The donations have the purpose of financing scientific work on behavioral addictions. But the donator has no influence on study-design, realization, analysis, interpretation or publication. The authors obtain no funding from the research fund of pro mente Upper Austria, Admiral Casinos \& Entertainment Corporation or any other company of the gambling branch. IMAS International has no connection to Admiral Casinos \& Entertainment Corporation or any other company of the gambling branch.

\section{Conflict of interest:}

Independently of this paper Kurosch Yazdi has commercial associations with Janssen Cilag, Amomed, Krka and Lundbeck as lecturer.

\section{References}

1. Elton-Marshall T, Leatherdale ST \& Turner NE: An examination of internet and land-based gambling among adolescents in three Canadian provinces: results from the youth gambling survey (YGS). BMC Public Health 2016; 16:277.

2. Götestam $K G$, Johansson A, Wenzel HG \& Simonsen IE: Validation of the lie/bet screen for pathological gambling on two normal population data sets. Psychol Rep 2004; 95:1009-13.

3. Griffiths M, Wardle H, Orford J, Sproston $K \&$ Erens Bl: Sociodemographic correlates of internet gambling: 
findings from the 2007 british gambling prevalence survey. Cyberpsychol Behav 2009; 12:199-202.

4. Johnson EE, Hamer R, Nora RM, Tan B, Eisenstein $N$ \& Engelhart C: The Lie/Bet Questionnaire for screening pathological gamblers. Psychol Rep 1997; 80:83-88.

5. Kairouz S, Paradis $C \&$ Nadeau L: Are online gamblers more at risk than offline gamblers? Cyberpsychol Behav
Soc Netw 2012; 15:175-180.

6. Kalke J, Buth S, Rosenkranz M, Schütze C, Oechsler $H$ \& Verthein U: Glücksspiel und Spielerschutz in Österreich. Lambertus, Freiburg, 2011.

7. Malischnig D: Online Gaming - Potential Risk and prevention programs. Psychiatr Danub 2014; 26:384388.

Correspondence:

Kurosch Yazdi, MD

Department of Psychiatry - Specialization Addiction Medicine

Kepler University Hospital

Wagner-Jauregg Weg 15, A - 4020 Linz, Austria

E-mail: kurosch.yazdi@gespag.at 